\title{
Initial Results from a Reconnaissance of Cyanobacteria and Associated Toxins in Illinois, August-October 2012
}

\author{
By Paul J. Terrio', Lenna M. Ostrodka', Keith A. Loftin², Gregg Good ${ }^{3}$, and Teri Holland ${ }^{3}$
}

\section{Abstract}

Ten lakes and two rivers in Illinois were sampled in August-October 2012 to determine the concentrations and spatial distribution of cyanobacteria and associated cyanotoxins throughout the State. The reconnaissance was a collaborative effort of the U.S. Geological Survey and the Illinois Environmental Protection Agency. Sample results indicated that concentrations of both total cyanobacterial cells and microcystin were commonly at levels likely to result in adverse human health effects, according to World Health Organization guidance values. Concentrations generally decreased from August to October following precipitation events and lower temperatures.

\section{Introduction}

Cyanobacteria, also known as blue-green algae, can be found in surface waters throughout the United States. These microscopic organisms, when present in high concentrations, can cause the water to have a pea-soup appearance or they can accumulate as floating masses of blue- or green-colored scum, commonly called cyanobacterial blooms. Elevated nutrient concentrations, slow-moving water, warm temperatures, and sunlight are all thought to be conducive to the growth of cyanobacteria.

The presence of cyanobacteria in lakes and rivers can pose risks to human and ecological health. Some species of cyanobacteria produce toxins, known as cyanotoxins, which can cause gastroenteritic problems if ingested or inhaled. Cyanotoxins can also cause allergic reactions following bodily contact (Graham and others, 2009). In addition to toxin production, cyanobacteria also can produce taste-and-odor compounds, which increase the cost of water treatment (Graham and others, 2008). Consequently, cyanobacteria in Illinois lakes and rivers may hinder recreational activities, contaminate drinking-water supplies, and pose health risks.

A reconnaissance was conducted by the U.S. Geological Survey (USGS) and the Illinois Environmental Protection Agency (EPA) during August-October 2012 to (1) confirm recent detections of high cyanotoxin concentrations, (2) assess the spatial extent, concentrations, and characteristics of cyanobacterial blooms in Illinois, and (3) provide data to support State and local agencies in managing water resources to protect human, animal, and ecological health. This report summarizes initial results from this effort for informational and discussion purposes. A more detailed publication with all

${ }^{1}$ U.S. Geological Survey, Illinois Water Science Center, Urbana, Illinois.

${ }^{2}$ U.S. Geological Survey, Kansas Water Science Center, Lawrence, Kansas.

${ }^{3}$ Illinois Environmental Protection Agency, Springfield, Illinois. methods, analytical results, and interpretations is planned. In late August 2012, concerns arose after samples analyzed from a private lake indicated elevated concentrations of cyanotoxins and several observations of cyanobacterial blooms in northern Illinois were reported. The two agencies made an effort to collect a substantial number of samples prior to both the Labor Day weekend and imminent rainfall and cooler temperatures (remnants of Hurricane Isaac), which could potentially alter the cyanobacterial communities and cyanotoxin concentrations. Illinois EPA field screening for cyanotoxins earlier in 2012 and in previous years detected few concentrations of concern. An extended drought in 2012 and accompanying high temperatures might have provided conditions facilitating cyanobacterial dominance and associated cyanotoxin production.

\section{Methods}

\section{Study design}

Between August 29 and September 4, 2012, ten lakes and two rivers were sampled for cyanobacteria, cyanotoxins, nutrients, and chlorophyll $a$ (fig. 1). The water bodies sampled were selected based on reports of current cyanobacterial blooms, where cyanobacterial blooms had been observed in the past, where other field efforts already were being conducted, and where additional sites would improve longitudinal distribution of sample locations throughout Illinois. Additional samples were collected on October 24, 2012, at four sites (three lakes and one river) where some of the highest cyanotoxin concentrations were determined in August-September samples.

\section{Field measurements}

Field measurements of water temperature, specific conductance, dissolved oxygen, and $\mathrm{pH}$ were collected by using multi-meter sensors. All sensors were calibrated according to individual agency protocols the day of the sampling. Field measurements were made approximately 1 foot below the water surface and within 10 feet of the water-sampling location, so as not to disturb the water column at the point of sample collection. Field measurement values reported here are considered preliminary pending agency review and approval.

\section{Sample collection}

Cyanobacterial samples from lakes were collected at or near the shoreline or from a dock. Samples from rivers were collected near the banks or from a bridge at the center of the stream. All samples were collected from observed cyanobacterial blooms or areas of cyanobacterial accumulation, if present. Samples were collected by immersing and subsequently filling 
polyethylene bottles by hand or by using a weighted-bottle sampler. Samples were collected at the surface of the water. To minimize sample disturbance, bottles were pre-rinsed in the target lake or river away from where samples were collected. Samples were placed in a dark cooler with ice to be analyzed for cyanotoxins, cyanobacteria identification and enumeration, total nutrients, and chlorophyll $a$.

\section{Laboratory analyses}

Samples collected for cyanotoxin analyses were frozen to arrest cyanobacerial growth and chemical alteration before being sent for analysis to the USGS Organic Geochemical Research Laboratory (OGRL), Lawrence, Kansas. Samples were analyzed by using enzyme-linked immunosorbent assays (ELISA) to determine the presence of three cyanotoxins: microcystins, saxitoxins, and cylindrospermopsins. Subsequent tandem mass spectrometry was run on selected samples to determine the concentrations of several additional cyanotoxins, in addition to a verification of the ELISA results, where possible.

Cyanobacteria samples from each water body were collected in 500-milliliter $(\mathrm{mL})$ polyethylene bottles and preserved with approximately $5 \mathrm{~mL}$ of Lugol's solution. The samples were subsequently shipped to GreenWater Laboratories, Palatka, Florida, for cyanobacterial species identification and enumeration.

Water samples to be analyzed for nutrients were also collected as grab samples and were preserved with sulfuric acid before shipment to the Illinois EPA laboratory in Springfield, Illinois. These samples were analyzed for total phosphorous, total inorganic nitrogen, total organic plus ammonia nitrogen, and total ammonia nitrogen using Illinois EPA-approved methods.

Chlorophyll $a$ samples were collected in polyethylene bottles and filtered onsite onto a glass-fiber filter by using a hand vacuum pump. The sample filters were subsequently frozen before being shipped to the Illinois EPA laboratory for analysis per approved methods.

\section{Results and Discussion}

Samples collected in late August and early September had a wide range of cyanotoxin concentrations and total cyanobacterial cell counts (table 1). Results from the ELISA analyses showed that microcystins were the most frequently detected cyanotoxin and were found in 85 percent of the water bodies. Cylindrospermopsins were detected in 3 samples and at concentrations near the detection limit, and saxatoxins were not detected at any sampling site. Preliminary results from the mass spectroscopy analyses also indicated that microcystins were the predominant cyanotoxin present in the samples and were found in samples from 11 of the 13 sampling sites.

The highest total microcystin concentration $(4,800 \mu \mathrm{g} / \mathrm{L})$ was found in a northern Illinois lake-one of the lakes where concerns about cyanobacterial blooms was first expressed. Lower concentrations (less than $2 \mu \mathrm{g} / \mathrm{L}$ ) of total microcystin were found in six lakes and all rivers. Total cyanobacterial cell counts also ranged broadly from the lowest count of 11,050 cells $/ \mathrm{mL}$ in the Vermilion River to the highest count of $84,570,000$ cells $/ \mathrm{mL}$ in a northern Illinois lake.
The World Health Organization (WHO) developed guidance values for the relative probability of adverse human health effects from recreational exposure to microsytin-LR (a common microcystin variant) and total cyanobacteria (Chorus and Bartram, 1999). The explanation on figure 1 shows these guidance values and the likelihood of associated adverse health effects designated as low, moderate, high, and very high probabilities. By comparison with these guidance values, four lakes but no rivers were found to have high probabilities of health effects due to microcystin. For total cyanobacterial cell counts, virtually all of the water bodies had high or very high probabilities of associated health effects; the exceptions were a private lake in western Illinois and the Vermilion River.

Preliminary results from the October 2012 samples indicate that both total microcystin concentrations and total cyanobacterial counts decreased from late August or early September to October, 2012. Both total microcystin concentrations and total cyanobacterial cell counts decreased approximately one order of magnitude in samples collected from these two periods; microcystin concentrations for Westlake decreased approximately one-hundredfold. Both water temperature and $\mathrm{pH}$ were observed to have decreased at several sites between the August and October sample-collection dates.

The results from 13 water bodies sampled in 2012 indicate that cyanobacteria and associated cyanotoxins are a concern for Illinois residents and water-resource managers and agencies. The drought conditions and accompanying hot temperatures present during much of the summer in 2012 might have affected the development and persistence of cyanobacterial blooms. However, relatively little is still understood about the specific conditions that cause cyanobacterial blooms to occur and what causes the cyanotoxin. Further study and monitoring of the development and distribution of cyanobacterial blooms is needed to determine the best approaches and practices to managing Illinois surface waters.

\section{Acknowledgments}

The authors would like to acknowledge the sample-collection efforts of Diane Tancl and Mike Bundren of the Illinois Environmental Protection Agency and David Fazio, Charles Bohall, and Jacob Wikle of the Illinois Water Science Center. We would also like to thank the communities and owners of the water bodies that were sampled for this effort.

\section{References}

Chorus, I., and Bartram, J., eds., 1999, Toxic cyanobacteria in water: London, World Health Organization, 416 p.

Graham, J.L., Loftin, K.A., Ziegler, A.C., and Meyer, M.T., 2008, Guidelines for design and sampling for cyanobacterial toxin and taste-and-odor studies in lakes and reservoirs: U.S. Geological Survey Scientific Investigations Report 2008-5038, 39 p.

Graham, J.L., Loftin, K.A., and Kamman, N., 2009, Monitoring recreational freshwaters - State monitoring programs for cyanobacterial toxins in recreational freshwaters of the United States: Lakeline, Summer 2009, p. 18-24. 


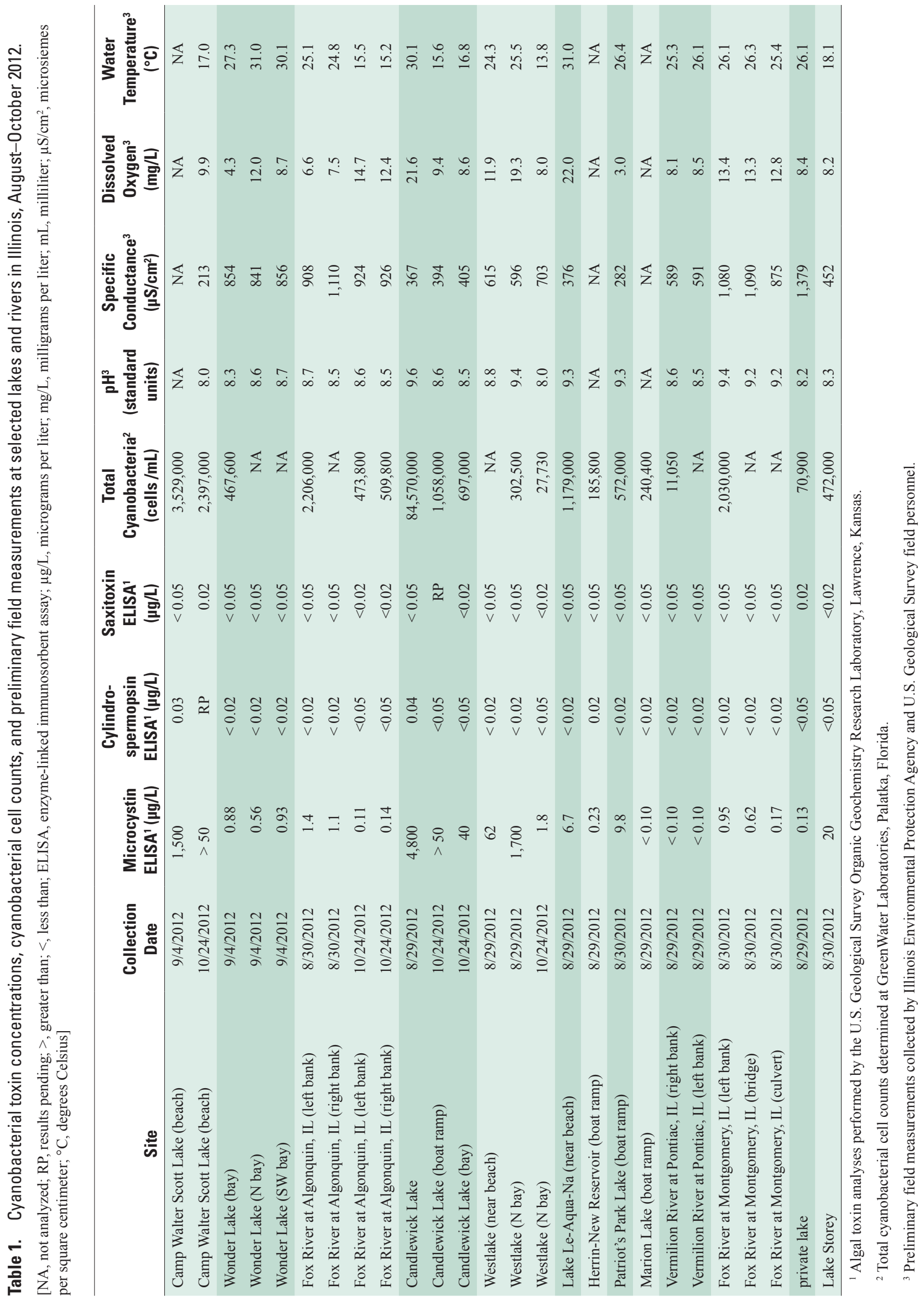




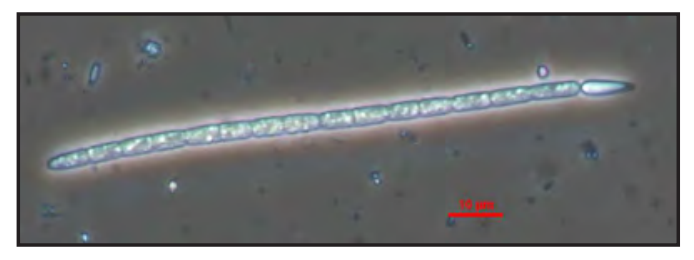

Top: Cylindrospermopsis raciborskii (photo reproduced with permission from GreenWater Laboratories)

Middle: Microcystis aeruginosa (photo reproduced with permission from GreenWater Laboratories)

Bottom: Algae on Patriot's Park Lake (photo by Mike Bundren, Illinois EPA)
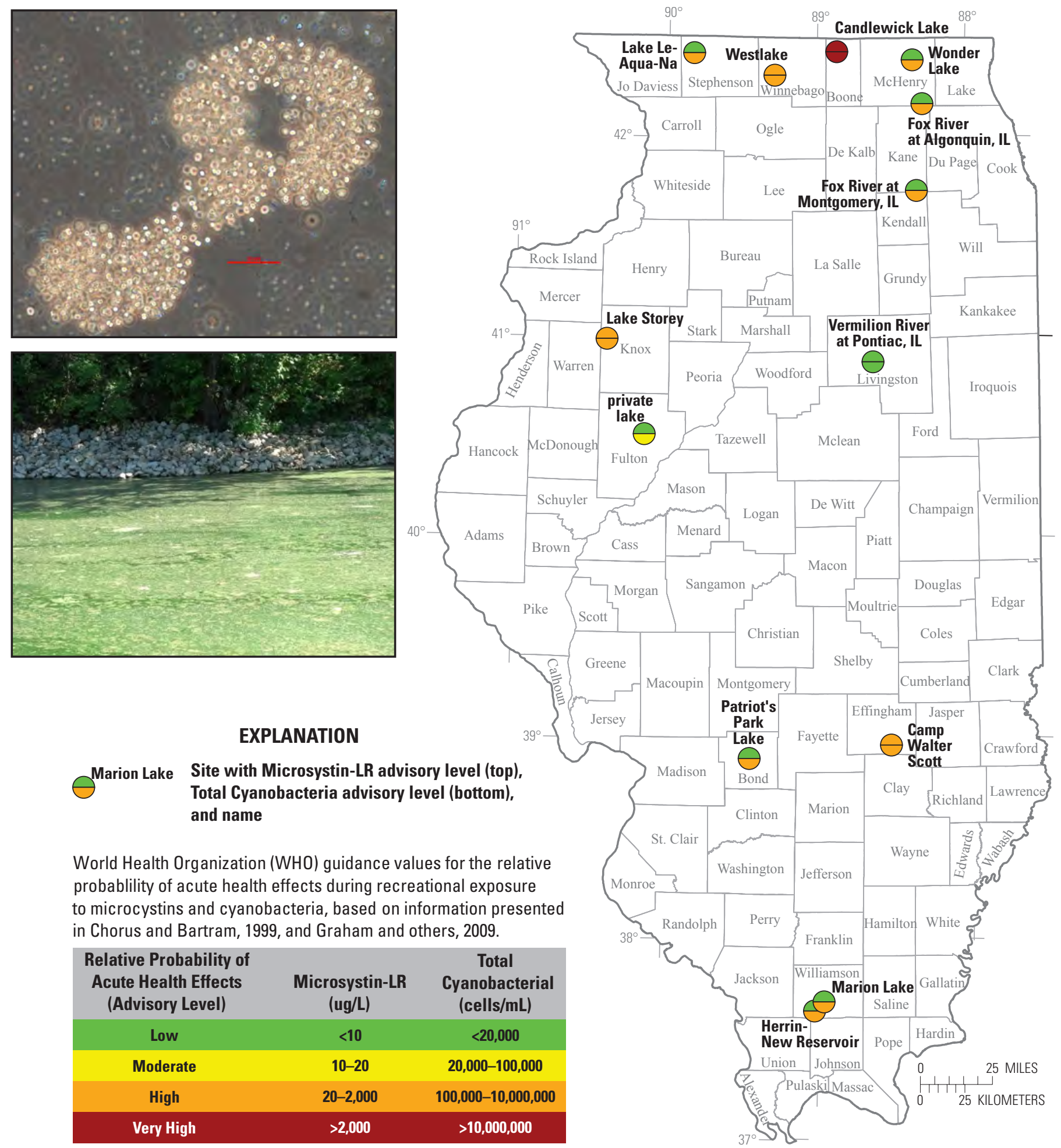

EXPLANATION

Marion Lake

Site with Microsystin-LR advisory level (top) Total Cyanobacteria advisory level (bottom), and name

World Health Organization (WHO) guidance values for the relative probablility of acute health effects during recreational exposure to microcystins and cyanobacteria, based on information presented in Chorus and Bartram, 1999, and Graham and others, 2009.

\begin{tabular}{ccc}
$\begin{array}{c}\text { Relative Probability of } \\
\begin{array}{c}\text { Acute Health Effects } \\
\text { (Advisory Level) }\end{array}\end{array}$ & $\begin{array}{c}\text { Microsystin-LR } \\
\text { (ug/L) }\end{array}$ & $\begin{array}{c}\text { Total } \\
\text { Cyanobacterial } \\
\text { (cells/mL) }\end{array}$ \\
\hline Low & $<10$ & $<20,000$ \\
\hline Moderate & $10-20$ & $20,000-100,000$ \\
\hline High & $20-2,000$ & $100,000-10,000,000$ \\
\hline Very High & $>2,000$ & $>10,000,000$ \\
\hline
\end{tabular}

Figure 1. Cyanobacteria sampling sites in Illinois showing relative probability of acute health effects from microcystins and cyanobacterial cells based on maximum levels found in samples collected in 2012. 